\title{
A IMPLANTAÇÃO DE INFRAESTRUTURA NA CIDADE DE SÃO PAULO O CENTRO EXPANDIDO NO PERÍODO 1890-1999 ${ }^{1}$
}

\section{INFRASTRUCTURE DEPLOYMENT IN THE CITY OF SÃO PAULO THE EXPANDED CENTER IN THE PERIOD OF 1890-1999}

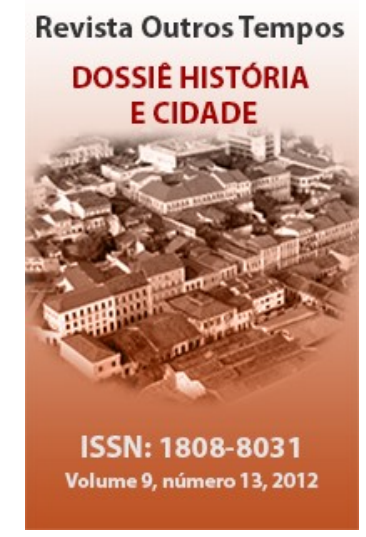

Pesquisadora Pós-Doutoranda em Infra-estrutura Urbana e Regional - USP

Butantã, SP-Brasil

vanessamassara@gmail.com

Resumo: Considerando a importância que as infraestruturas têm na qualidade de vida das cidades, o artigo apresenta a cronologia de implantação e expansão das redes na cidade de São Paulo, em especial no perímetro denominado centro expandido, durante 110 anos. Conclui-se que a área central, denominada neste artigo de centro histórico, é o núcleo do desenvolvimento das infraestruturas, seguida da região intitulada "distritos ao redor" que, com o passar do século XX, vai sofisticando seus usos do solo e atraindo, assim, novos serviços, como o cabo ótico. Ao final do período de estudo, verifica-se que todo o centro expandido é servido pelas redes, confirmando que a acelerada dinâmica urbana dessa área incentiva a introdução dos serviços em rede.

Palavras-chave: Infraestrutura. Cidade de São Paulo. Centro Expandido.

\begin{abstract}
Considering the importance of the infrastructure on the quality of life in cities, the paper presents the chronology of implementation and expansion of networks in the city of São Paulo, especially on the perimeter named "expanded center" for 110 years. We conclude that the central area, this article called "historic center" is the core of infrastructure development, then the region entitled "districts around" that, over the twentieth century will more sophisticated uses of their land and thus attracting new services such as optical cable. At the end of the study period, it appears that all the "expanded center" is served by the networks, confirming that the rapid urban dynamics of the area encourages the introduction of network services.
\end{abstract}

Key-words: Infrastructure. City of São Paulo. Expanded Center.

\footnotetext{
${ }^{1}$ Artigo submetido à avaliação em 27/02/2012 e aprovado para publicação em 30/05/2012

A pesquisa que resultou neste artigo contou com financiamento do CNPq e orientação do Prof. Livre-Docente Witold Zmitrowicz, Arquiteto Urbanista, aposentado do curso de Engenharia Urbana e Ambiental-USP e Vice-Diretor do Centro Inter unidade de História da Ciência - USP.
} 


\title{
Introdução
}

Mumford (1938, p.437) mostra, em uma visão histórica, como as redes de infra-estrutura ganharam importância no desenvolvimento das cidades, mencionando as questões de higiene no século XIX e a consequente implantação de sistemas de abastecimento de água e deposição de esgotos para suprir essa necessidade:

\begin{abstract}
A higiene acentuava a importância do fornecimento de água exigindo não simplesmente a pureza, mas aumentando continuadamente a quantidade necessária, à medida que os hábitos de banho e lavagem propagavam-se em ondas concêntricas de um a outro grupo econômico. Tais fatos mostram-se igualmente verdadeiros quanto aos sistemas de deposição de sobras e esgotos.
\end{abstract}

Comenta, ainda, as possibilidades criadas pelo uso da energia elétrica como parte do incentivo para a Revolução Industrial e da introdução do telefone:

Com novos meios de transporte e de geração de energia, vantagens locais, outrora concentradas num centro circunscrito, num único ponto, podem ser distribuídas através de toda uma região. Para completar tudo isso, o telégrafo, o telefone, o rádio já igualmente surgiam no complexo neotécnico.

O autor conclui o raciocínio com as modificações na cidade oriundas dessa evolução: "O efeito de todos esses instrumentos é o de aumentar a esfera de atividades ao mesmo tempo em que diminuem a necessidade de movimento físico, originando densa colonização e criando novos centros". Ainda sobre a expansão da cidade e as possibilidades criadas pela energia elétrica, mencionando o geógrafo Piotr Kropotkin, que enfatiza em obra de 1961 (p. 555) :

\footnotetext{
Quase meio século à frente da opinião econômica e técnica de seu tempo, havia ele aprendido o fato de que a flexibilidade e adaptabilidade da comunicação elétrica e da energia elétrica, juntamente com as possibilidades de cultivo intensivo e biodinâmico da terra, tinham lançado as bases de um desenvolvimento urbano mais descentralizado...
}

Também sobre a geração de energia, Cotrell (1955, p.108) trata da relação entre energia, mudanças sociais, desenvolvimento econômico e tecnológico, enfatizando que sua expansão ocorre:

...de forma a incrementar a produção de indústrias, a iluminação de vias públicas e através das estações transformadoras facilitando e tornando mais barato o alcance de maiores distâncias, propiciando a ocupação de áreas vazias, além de melhorar a condição de áreas já consolidadas. 
Mascaro (1987, p.17) enfatiza a relação entre a cidade e o conjunto de elementos (serviços e equipamentos) que propiciam seu pleno desenvolvimento:

\begin{abstract}
...do espaço urbano também fazem parte as redes de infraestrutura que possibilitam seu uso e, de acordo com sua concepção, se transformam em elemento de associação entre a forma, a função e a estrutura, ou contribuem para que o conjunto urbano se apresente como fragmentos de um catálogo incoerente de elementos que não estão articulados entre si.
\end{abstract}

Zmitrowicz e Angelis Neto (1997, p.2) definem as redes segundo sua função na cidade:

\begin{abstract}
A infraestrutura urbana pode ser conceituada como um sistema técnico de equipamentos e serviços necessários ao desenvolvimento das funções urbanas, podendo estas funções ser vistas sob aspectos social, econômico e institucional. Sob o aspecto social, a infra-estrutura urbana visa promover adequadas condições de moradia, trabalho, saúde, educação, lazer e segurança. No que se refere ao aspecto econômico, a infra-estrutura urbana deve propiciar o desenvolvimento das atividades produtivas, isto é a produção e comercialização de bens e serviços. E sob o aspecto institucional, entende-se que a infra-estrutura urbana deva propiciar os meios necessários ao desenvolvimento das atividades político-administrativas, entre os quais se inclui a gerência da própria cidade.
\end{abstract}

Em trabalho sobre Estruturação Territorial Urbana, Zmitrowicz (1997, p.13) resume o conceito: "Os conjuntos de redes de infraestruturas ligam os espaços urbanos às fontes de matéria, energia e informações, ou aos locais de disposição de matérias nocivas ou prejudiciais, interconectando as zonas urbanas com as zonas de seu entorno..."

Ainda no mesmo trabalho, conclui Zmitrowicz (1997, pg. 35):

\footnotetext{
...considerando as "infraestruturas" - energia, saneamento e comunicação como "fluxos" que conectam os locais em que se processa a 'produção' aos ambientes onde se processo o 'consumo', sua perfeita adequação no espaço, além de melhorar a qualidade de vida, favorece o crescimento da economia e o desenvolvimento integrado de todas as funções da cidade.
}

Com base nos estudos mencionados, buscamos um respaldo de informações no âmbito técnico sobre a evolução das redes de infra-estrutura no Município de São Paulo. Considerando o enfoque histórico sobre sua expansão, os trabalhos de Motta (1911), Novaes (1927), Andrade (1966), catálogos da SABESP (1976), Telles (1984) e os artigos da REVISTA D.A.E. (1936 - 1995) sobre os planos para a evolução do abastecimento de água e coleta de esgotos no Município forneceram material importante para caracterizar o incremento e os déficits dos sistemas. 
No campo da energia elétrica, a descrição histórica de Branco (1951), coletâneas da ELETROPAULO (1989; 1990), relatórios da CESP (1997) e consulta ao EMAE (2001) cobrem a análise histórica durante o século XX. Para a rede de gás, o relatório da COMGÁS (1997) e catálogos do seu acervo histórico propiciaram a obtenção de informações sobre a iluminação a gás e o uso do gás para aquecimento.

No campo das comunicações, Leão (1941) traz dados referentes às centrais telefônicas e densidade de aparelhos do início do século até 1940, informações completadas no catálogo do MUSEU DO TELEFONE (1977), que forneceu planilhas com dados de 1998/2000.

Sobre a introdução das redes de cabo óptico, Giozza (1991) e Nobre (2000) argumentam sobre a consequente otimização do setor de prestação de serviços e as mudanças no projeto de escritórios: espaços cada vez menores opondo-se às necessidades das décadas anteriores e à característica dos edifícios do Centro Histórico de São Paulo.

Os relatórios Públicos e de Órgãos não Governamentais ligados às questões urbanas forneceram as informações gráficas (mapas e esquemas) e os dados quantitativos da capacidade das redes.

O relatório da Associação Nacional dos Geógrafos, organizado por Azevedo (1958, 4 vol.), apresenta várias informações tanto sobre infra-estrutura como sobre o perfil sócio-econômico da população do início do século à década de 50. O PUB - Plano Urbanístico Básico (1968), através do volume 5: Infra-Estrutura, traça o perfil das redes através de mapas e dados quantitativos que foram combinados às informações sobre uso do solo e questões de expansão da cidade.

Os relatórios da Prefeitura de 1958 e 1975 (16 vol.) descrevem a condição das redes e possibilitaram a montagem dos primeiros mapas "rua a rua". O mapa de uso do solo de 1958, embora de baixa qualidade gráfica, serviu como um parâmetro para conclusões sobre as transformações da época.

Os Sumários de Dados (1977/1998) produzidos pela EMPLASA fornecem dados no campo do saneamento e da energia elétrica, que, após serem reunidos, foram transformados em tabelas que ajudam na caracterização da expansão dos serviços a partir da década de 70 .

Trabalhos da SEMPLA: Diagnóstico regionalizado do Município de São Paulo (1983) e Plano para cinco regiões administrativas do Município de São Paulo (1986) detalham a situação por região da cidade, fornecendo importantes considerações para as redes de iluminação pública e gás canalizado. Também o Plano do Município de São Paulo 1985/2000 (1985) colaborou com dados para a década de 80, principalmente para o saneamento, 
fornecendo tabelas com a captação dos mananciais da época e iluminação pública, com informações detalhadas sobre o salto na implantação desse serviço, verificado na primeira metade da década de 80. O caderno "Perfil Socioeconômico do Município de São Paulo" (2000/01), também produzido pela SEMPLA, detalha as alterações no uso do solo, resumindo informações a partir de 1980, e fornece características da população úteis para o perfil da década de 90.

Também os censos do IBGE de 1970 e 2000 foram de suma importância no tocante à descrição da condição das redes de abastecimento de água, coleta de esgotos e consumo de energia elétrica por tipo de uso, fornecendo valores para cada distrito. Deve-se ressaltar que a única dificuldade na utilização desses dados consiste na falta de concordância entre os perímetros utilizados por esse órgão e também pela Eletropaulo, e aqueles utilizados pela Prefeitura, Sempla e Sabesp (baseados na Lei de 1991 e na divisão em administrações regionais vigente até 2000).

\section{O centro expandido}

A combinação de dois fatores resultou na seleção do chamado centro expandido como objeto de estudo das redes de infra-estrutura. $\mathrm{O}$ primeiro deles está baseado na característica da região de concentrar todos os serviços (TOLEDO SILVA, 1995, p.19):

\footnotetext{
...os grandes entroncamentos de transporte de massa e os principais nós das redes de água, esgoto, energia elétrica, telefonia e gás encanado ou estão diretamente localizados na zona central ou estão à ela vinculados de forma praticamente irreversível, fornecendo condição ideal para expansão de usos e conseqüente desenvolvimento econômico.
}

O segundo refere-se a inter-relacionar este trabalho com outros estudos, visando a elaboração de um perfil da evolução do Município através da distribuição territorial das infra-estruturas e das transformações nos usos do solo, envolvendo fatores como valorização imobiliária, distribuição de renda e de população versus o desenvolvimento econômico e social de áreas centrais e periféricas.

O levantamento do avanço das redes de abastecimento de água, coleta de esgotos, gás canalizado, iluminação pública, cabo óptico e telefonia é separado em 4 períodos determinados pela massa de informações e suas datas de publicação: Primeiro Período: 1890-1922; Segundo Período: 1922-1952; Terceiro Período: 1952-1972; Quarto Período: 1972-1999. 
Cabe explicar que, quando é descrita a condição das redes e evolução da população e renda mensal, divide-se a área denominada neste trabalho como Centro Expandido em dois grupos: distritos do centro histórico e distritos ao redor ${ }^{2}$, com a intenção de uniformizar os dados com os perímetros e denominações de todos os órgãos envolvidos nesta pesquisa. Desta forma define-se aqui como centro expandido aproximadamente a soma dos distritos descritos no grupo "centro histórico" e no grupo "distritos ao redor". A figura 1 mostra o perímetro da região (EMPLASA, 1993).

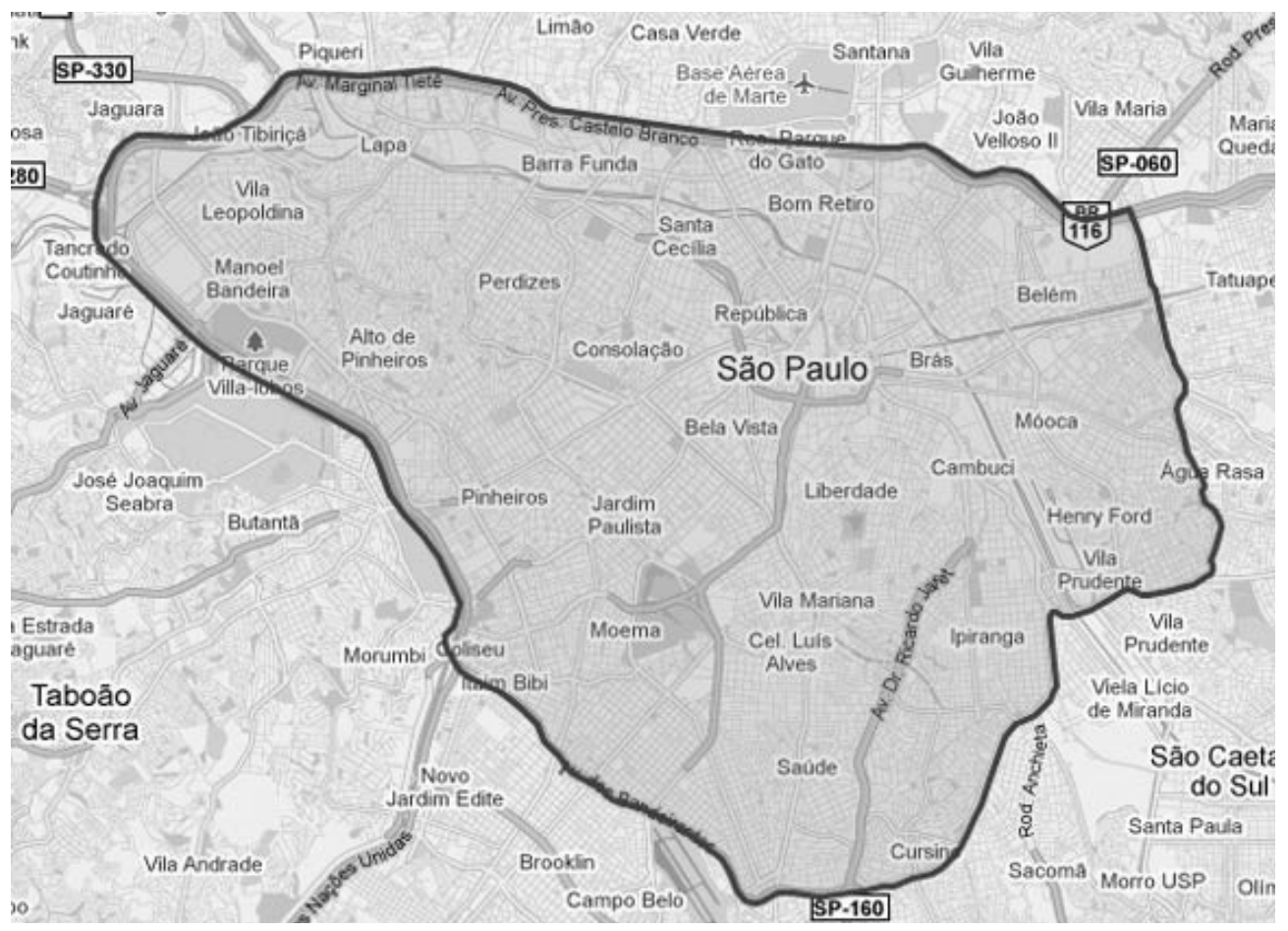

Figura 1. Centro expandido segundo Emplasa (1993). Nota: figura sem escala.

\section{Características urbanas}

\footnotetext{
${ }^{2}$ Com o objetivo de associar o histórico dos bairros a dados do IBGE e das concessionárias, usamos um perímetro aproximado que permita relacionar todas as denominações à divisão em distritos da Prefeitura (1991): -Distrito Moema: Moema, Indianópolis, Planalto Paulista;

-Distritos Vila Leopoldina e Lapa: Vilas Leopoldina, Hamburguesa e Anastácio, Alto da Lapa, Lapa de Baixo, Vila Romana;

-Distrito Pinheiros: Pinheiros, Alto de Pinheiros, Vila Madalena, Boaçava;

-Distrito Itaim Bibi: Itaim Bibi, Vila Olímpia, Vila Funchal;

-Distrito Vila Mariana: Vila Mariana, Ibirapuera;

-Distrito Jardim Paulista e Consolação: Cerqueira César, Paraíso, Jardim Paulista, Jardim América, Jardim Europa, Jardim Paulistano, Consolação;

-Distrito Sé: Sé, Santa Ifigênia e Luz;

-Distrito Santa Cecília: Campos Elíseos, Santa Cecília, Higienópolis, Vila

Buarque;

-Distrito Barra Funda: Água Branca, Barra Funda;

-Distritos Liberdade e Cambuci: Liberdade, Aclimação, Cambuci
} 
A história da formação do centro confunde-se, em parte, com a história do desenvolvimento de São Paulo.

A escolha do local para fixação do colégio indigenista - o promontório, na proximidade da ligação entre os rios Anhangabaú e Tamanduateí - definiu o marco de expansão urbana da cidade.

Até o século XVIII, houve pouco desenvolvimento; alguns bairros formaram-se ao redor das igrejas $^{3}$ e dos Caminhos das $\operatorname{Tropas}^{4}$ (TELLES, 1984). No século seguinte, a ocupação foi intensificada ao redor dos chafarizes públicos para abastecimento de água e, a partir de 1867, ao longo do traçado das ferrovias ${ }^{5}$. Já no final deste período, diversos fatores contribuíram para a expansão da cidade: a abolição da escravatura, a chegada dos imigrantes e a proclamação da República, a quebra do Banco Mauá desencadeando um processo de loteamento das chácaras, transformando o investimento em terras em um mercado lucrativo e considerado como o único realmente seguro:

\begin{abstract}
...quase todos os proprietários de antigas chácaras, que então existiam nos bairros de Santa Efigênia, Bom Retiro, Brás, Consolação, Liberdade e Cambuci, mandaram abrir diversas ruas, avenidas, alamedas e largos. (MARTINS, s.d. p.163-164).
\end{abstract}

No início do período de estudo, a cidade ainda passava pelo processo de loteamento das chácaras, com grandes vazios separando as áreas centrais de núcleos localizados a grandes distâncias, como Santo Amaro, Pinheiros, Nossa Senhora do Ó, Ipiranga, Nossa Senhora da Penha, São Miguel Paulista, entre outros, fugindo das várzeas e seguindo a topografia, enfrentando problemas na transposição dos rios e com o suprimento de água.

A Estação da Luz e a Estação do Norte, no Brás, próximo à Hospedaria dos Imigrantes, formou um pequeno centro de atividades e reduto do operariado. Da mesma forma, a Lapa, Barra Funda e Água Branca, a noroeste, prolongaram a faixa de característica industrial e proletária, ligando Pari, Brás, Belenzinho e Mooca.

O sul e sudoeste não possuíam a linha férrea, e passaram a ser ocupados por residências. A subdivisão das chácaras de Santa Efigênia e Campos Elíseos concentrou os interesses da elite em ascensão, assim como parte da Praça da República. O avanço dessa elite

\footnotetext{
${ }^{3}$ Como no caso do Brás, tendo o núcleo inicial ao redor da igreja de Bom Jesus dos Matosinhos.

${ }^{4}$ Esses caminhos funcionavam como ligação entre as "freguesias" e também na ligação da província com outros Estados. Como exemplos, podemos citar o bairro da Luz, ligação para Santana, Sul de Minas, São João de Atibaia, Nazaré, Juqueri e Conceição dos Guarulhos (Caminho do Guaré); o bairro da Lapa, pela Ponte do Anastácio, na ligação com a Vila de Itu. E os Caminhos do Mar, para Santo Amaro (caminho do Carro), para Penha de França e Água Branca; Rua da Consolação, caminho para Sorocaba, entre outros.

${ }^{5}$ Como os bairros do Ipiranga, Mooca, Cambuci, Brás, Pari, Barra Funda, Água Branca e Lapa.
} 
através de Higienópolis até a Avenida Paulista prosseguiu a sudoeste e formou os Jardins. A expansão seguinte é caracterizada pela formação de áreas de uso misto, concentrada no aumento de edifícios e comércio, estendendo-se a Perdizes, Bela Vista e Liberdade (ANDRADE, 1966).

Com esta nova visão, os limites precisos do terreno passam a ser importantes, bem como a preocupação sobre o alinhamento e demarcação da servidão pública. Tem início a formação de bairros sob a divisão da cidade em classes sociais. As tradicionais famílias paulistanas e os bem-sucedidos comerciantes europeus ocupam primeiro os Campos Elíseos e, a seguir, Higienópolis, a Avenida Paulista e os Jardins ${ }^{6}$, e mais tarde expandem-se para a zona oeste; o chamado "Triângulo", formado pelas ruas Direita, XV de Novembro e São Bento, ganha importância como espaço elegante de comércio e lazer. A construção do Viaduto do Chá expande os limites para a Praça da República e consolida o "centro novo".

Operários nacionais e vindos de outros países, principalmente da Itália, espalham-se pelos bairros populares de características industriais: Bom Retiro, Barra Funda, Brás, Cambuci, entre outros. Ex-escravos e imigrantes ocupam bairros como Santa Efigênia e Bela Vista, sob a forma de cortiços tidos como "ninhos de tuberculose", e que deveriam ser retirados das áreas centrais.

Havia então dois grandes ramos no negócio imobiliário: os bairros residenciais, bem servidos de infraestrutura, e o subúrbio, um espaço ainda não regulado pela legislação. A expansão da cidade a partir de 1920, tendo como base as facilidades oriundas da introdução do automóvel e ônibus como meios de transporte e dos projetos viários - como a implantação de alguns projetos de Planos de Avenidas ${ }^{7}$, dá novo impulso a cidade (AZEVEDO, 1958).

Com o processo de desindustrialização local, parte da área industrial do Pari e Brás, e depois toda a extensão, começando da Vila Leopoldina, torna-se de uso misto.

O processo de "verticalização", iniciado entre os anos 40 e 50 e enfatizado na década de 70, traz diversos estilos arquitetônicos, mudanças de gabarito na determinação de altura e de coeficientes de aproveitamento pelas determinações das leis de zoneamento, e vai se tornando um importante mecanismo da indústria imobiliária.

A enorme verticalização tomou conta de vasta área desde Perdizes até Moema, e a sudeste, na Liberdade, Aclimação e parte do Cambuci, sendo intercalada apenas com pontos ocupados pela elite, e protegidos pela legislação nos Jardins América e Europa e no

\footnotetext{
${ }^{6}$ Correspondendo ao conjunto formado pelo Jardim Paulista, Jardim Paulistano, Jardim Europa e Jardim América.

${ }^{7}$ Quando é mencionado o Planos de Avenidas, é feita a menção a todos os projetos para o sistema viário, como os de Prestes Maia e outros anteriores.
} 
Ibirapuera. O Alto da Lapa e Alto de Pinheiros também se mantiveram como bairros para a classe de maior renda. Os bairros a sudoeste da cidade (Pinheiros, Itaim Bibi, Moema e Ibirapuera) adquirem o aspecto de região para a classe média e alta.

A influência das melhorias no sistema viário e nos meios de transporte não está inclusa nesta pesquisa, mas não se pode deixar de mencioná-la como fator de desenvolvimento: a estrada de ferro na formação dos bairros populares e as importantes avenidas na concentração de edifícios residenciais e de prestação de serviços (BARBOSA, 2001).

Outros centros são criados. O centro antigo, saturado e congestionado, expande-se, nos anos 60, para a Avenida Paulista. Embora outros núcleos de prestação de serviços tenham sido formados nos últimos decênios, como os das avenidas Brigadeiro Faria Lima e Luis Carlos Berrini, a importância da Avenida inaugurada há mais de um século ainda é preponderante $^{8}$.

\section{População}

Com exceção do pico de crescimento demonstrado no censo de 1980 para os distritos ao redor do antigo centro, fica evidente a tendência de evasão da população de forma gradativa nas décadas de 70 e 80 , e com grande ênfase nos anos 90; os motivos diversos que induziram essa reação, entre eles, o baixo preço de terrenos na periferia, suplantaram importantes facilidades proporcionadas pela região, como a proximidade de pólos empregatícios e presença de serviços (tabela 1).

Tabela 1. Evolução da população (hab) do Centro Expandido. Fonte: EMPLASA (1977,/1998); IBGE, 2000; PMSP, 1975; SEMPLA, 2001.

Nota. Informações anteriores à década de 60 não puderam ser agrupadas nos distritos oficiais determinados em 1991.

\footnotetext{
${ }^{8}$ Sobre usos do solo, consultar a dissertação de BARBOSA (2001, vide referências), que focaliza a dinâmica das transformações no uso do solo no século XX para a região do centro expandido segundo os limites determinados pela Emplasa, relacionando essas modificações às alterações na lei de zoneamento e a expansão dos bairros.
} 


\begin{tabular}{|c|c|c|c|c|c|}
\hline centro histórico & 1960 & 1970 & 1980 & 1991 & 2000 \\
\hline Sé & 8880 & 8049 & 8207 & 5795 & 14227 \\
\hline Barra Funda & 32454 & 29762 & 30685 & 25680 & 11708 \\
\hline Belém & 63153 & 52238 & 49273 & 43746 & 35582 \\
\hline Bom Retiro & 26457 & 25606 & 25068 & 19283 & 19080 \\
\hline Brás & 63971 & 54391 & 48588 & 40313 & 19182 \\
\hline Cambuci & 49900 & 48600 & 53590 & 48258 & 26675 \\
\hline Pari & 35000 & 30693 & 27748 & 21899 & 7736 \\
\hline República & ------- & ------- & ------- & ------ & 41978 \\
\hline Mooca & 42792 & 35298 & 36175 & 41314 & 56381 \\
\hline Santa Ifigênia & 47252 & 38980 & 42551 & 36341 & ------ \\
\hline total & 324567 & 286607 & 281314 & 248279 & 234549 \\
\hline \multicolumn{6}{|l|}{ distritos ao redor } \\
\hline Consolação & 51698 & 62226 & 72374 & 65009 & 51174 \\
\hline Alto de Pinheiros & -------- & ------- & ------ & ------ & 38323 \\
\hline Lapa & 105995 & 122512 & 135515 & 120794 & 56151 \\
\hline Liberdade & 55873 & 59790 & 73383 & 66110 & 53930 \\
\hline Moema &  & -- & ----- & - & 71148 \\
\hline Bela Vista & 57825 & 61192 & 79367 & 65521 & 58472 \\
\hline $\mathrm{P}$ & 91310 & 100161 & 127935 & 119269 & 99178 \\
\hline Pin & 36201 & 44080 & 47129 & 40070 & 61377 \\
\hline Jardim Paulista & 80173 & 91927 & 116450 & 106327 & 77584 \\
\hline Santa Cecília & 60501 & 67899 & 84956 & 78637 & 67010 \\
\hline Itaim Bibi & ----- & ------ & ------- & ------- & 73280 \\
\hline Vila Leopoldina & --- & ----- & ------ & ----- & 26042 \\
\hline Indianópolis & 53303 & 70721 & 82658 & 84133 & ------- \\
\hline Aclimação & 44230 & 49058 & 55364 & 52112 & ------- \\
\hline Jardim $A$ & 42683 & 47197 & 55291 & 48129 & ------- \\
\hline Cerq & 32040 & 43616 & 65447 & 57032 & ------- \\
\hline Vila $N$ & 30112 & 33825 & 48296 & 43147 & ------- \\
\hline Vila Mariana & 76899 & 80919 & 108282 & 99142 & 116772 \\
\hline total & $\mathbf{8 1 8 8 4 3}$ & 935123 & 1152447 & 1045432 & 850441 \\
\hline total geral & 1143410 & 1221730 & 1433761 & 1293711 & 1084990 \\
\hline
\end{tabular}

\section{Renda Mensal}

O chamado Centro Histórico apresenta menor concentração de renda quando comparado com os distritos ao redor; mesmo assim, a maioria dos distritos são considerados de classe média; segundo a Sempla, somente a Sé e o Belém têm condição sócioeconômica baixa.

Já a região ao redor reúne os maiores índices de renda mensal do Município. 0s distritos do Alto de Pinheiros, Moema, Jardim Paulista, Itaim Bibi, Pinheiros, Perdizes e Vila Mariana estão no grupo de condição socioeconômica alta, confirmando a característica da região de constituir a área mais rica da cidade (tabela 2).

Tabela 2. Evolução da renda mensal no centro expandido. Fonte: EMPLASA (1977,/1998); IBGE, 2000; PMSP, 1975; SEMPLA, 2001.

Nota. Informações anteriores à década de 60 não puderam ser agrupadas nos distritos oficiais determinados em 1991. 


\section{Densidade Demográfica}

\begin{tabular}{|c|c|c|c|c|}
\hline centro histórico & de 5 a 10 SM & de 10 a $15 \mathrm{SM}$ & de 15 a $21 \mathrm{SM}$ & $\begin{array}{l}\text { superior a } 21 \\
\text { SM }\end{array}$ \\
\hline $\begin{array}{l}\text { Sé } \\
\text { Barra Funda } \\
\text { Belém } \\
\text { Bom Retiro } \\
\text { Brás } \\
\text { Cambuci } \\
\text { Pari } \\
\text { República* } \\
\text { Mooca }\end{array}$ & $\begin{array}{l}\text { década } 60 / 70 / 80 / 90 \\
\text { década } 60 / 70 / 80 \\
\text { década } 60 / 70 / 80 / 90 \\
\text { década } 60 / 70 / 80 / 90 \\
\text { década } 60 / 70 / 80 / 90 \\
\text { década } 60 / 70 / 80 / 90 \\
\text { década } 60 / 70 / 80 / 90 \\
\text { década } 60 / 70 / 80 / 90\end{array}$ & $\begin{array}{l}\text { década } 90 \\
\text { década } 90 \\
\text { década } 90\end{array}$ & & \\
\hline \multicolumn{5}{|l|}{ distritos ao redor } \\
\hline $\begin{array}{l}\text { Consolação } \\
\text { Alto de Pinheiros* } \\
\text { Lapa } \\
\text { Liberdade } \\
\text { Moema** } \\
\text { Bela Vista } \\
\text { Perdizes } \\
\text { Pinheiros } \\
\text { Jardim Paulista } \\
\text { Santa Cecília } \\
\text { Itaim Bibi** } \\
\text { Vila Leopoldina* } \\
\text { Indianópolis*** } \\
\text { Vila Mariana }\end{array}$ & $\begin{array}{l}\text { década } 60 / 70 / 80 \\
\text { década } 60 / 70 / 80\end{array}$ & $\begin{array}{l}\text { década } 90 \\
\text { década } 90 \\
\text { década } 60 / 70 / 80 / 90 \\
\text { década } 60 / 70 / 80 \\
\text { década } 60 / 70 / 80 \\
\text { década } 60 / 70 / 80 / 90 \\
\text { década } 90 \\
\text { década de } 60 / 70 / 80\end{array}$ & $\begin{array}{l}\text { década } 60 / 70 / 80 / 90 \\
\text { década } 90 \\
\text { década } 90 \\
\text { década } 60 / 70 \\
\text { década } 90 \\
\text { década } 60 / 70 / 80\end{array}$ & $\begin{array}{l}\text { década } 90 \\
\text { década } 90 \\
\text { década } 80 / 90 \\
\text { década } 90\end{array}$ \\
\hline
\end{tabular}

*sem dados específicos para décadas anteriores

** considerando para as décadas anteriores a 90 os dados de Indianópolis

*** dados da década de 90 associados aos distritos Moema e Itaim Bibi

Entre as décadas de 60 e 70, a maioria dos distritos ao redor do Centro Histórico, apresentavam crescimento de até 39\%. Já aqueles da área mais antiga, mostravam imensa redução.

No último decênio, a maior diminuição ocorreu na Barra Funda (densidade atual de 25,6 hab/Ha), embora todos os outros distritos tenham sofrido redução de população. As maiores densidades estão localizadas na Bela Vista $(249,6$ hab/Ha) e na República $(215,94$ hab/Ha). A tabela 3 resume as concentrações demográficas nas áreas de estudo.

Tabela 3 Faixas de densidade demográfica segundo os distritos. Fonte: EMPLASA (1977,/1998); IBGE, 2000; PMSP, 1975; SEMPLA, 2001. 


\begin{tabular}{|c|c|c|c|c|}
\hline centro histórico & até 80 hab/HA & até $150 \mathrm{hab} / \mathrm{HA}$ & $\begin{array}{l}\text { até } 150 \text { a } 250 \\
\text { hab/HA }\end{array}$ & \begin{tabular}{|l} 
superior a \\
$250 \mathrm{hab} / \mathrm{HA}$ \\
\end{tabular} \\
\hline $\begin{array}{l}\text { Sé } \\
\text { Barra Funda } \\
\text { Belém } \\
\text { Bom Retiro } \\
\text { Brás } \\
\text { Cambuci } \\
\text { Pari } \\
\text { República* } \\
\text { Mooca }\end{array}$ & $\begin{array}{l}\text { década } 70 / 80 \\
\text { década } 90 \\
\text { década } 70 / 80 / 90 \\
\text { década } 70 / 80 / 90 \\
\text { década } 70 / 80 / 90\end{array}$ & $\begin{array}{l}\text { década } 90 \\
\text { década } 70 / 80 \\
\text { década } 70 / 80 / 90 \\
\text { década } 70 / 80 / 90 \\
\text { década } 70 \\
\text { década } 70 / 80 / 90\end{array}$ & década 80/90 & \\
\hline distritos ao redor & & & & \\
\hline $\begin{array}{l}\text { Consolação } \\
\text { Alto de Pinheiros* } \\
\text { Lapa } \\
\text { Liberdade } \\
\text { Moema* } \\
\text { Bela Vista } \\
\text { Perdizes } \\
\text { Pinheiros } \\
\text { Jardim Paulista } \\
\text { Santa Cecília } \\
\text { Itaim Bibi* } \\
\text { Vila Leopoldina* } \\
\text { Indianópolis* } \\
\text { Vila Mariana }\end{array}$ & década $70 / 80 / 90$ & $\begin{array}{l}\text { década } 70 / 80 \\
\text { década } 70 / 80 \\
\text { década } 70 \\
\text { década } 70 / 80 / 90 \\
\text { década } 90 \\
\text { década } 70 / 80 / 90 \\
\text { década } 70 / 80 / 90 \\
\text { década } 70 / 80 / 90\end{array}$ & $\begin{array}{l}\text { década } 70 / 90 \\
\text { década } 90 \\
\text { década } 80 / 90 \\
\text { década } 70 / 80 \\
\text { década } 70 / 80 / 90 \\
\text { década } 70 / 80 \\
\text { década } 70 / 90\end{array}$ & década 90 \\
\hline
\end{tabular}

*dados estimados pela impossibilidade de definir mudança de área ao longo das três décadas de estudo

Nota. Informações anteriores à década de 60 não puderam ser agrupadas nos distritos oficiais determinados em 1991.

\section{Densidade Construída}

Este índice reflete a variação da densidade demográfica, bem como a concentração de renda, resultando em maior investimento em construção nos bairros de classe média e alta e consequente aumento na quota de ocupação por habitante. 
Tabela 3.4. Evolução da densidade construída no centro expandido. Fonte: PMSP, 1975; Sempla, 2001; IBGE,

\begin{tabular}{|c|c|c|c|c|}
\hline centro histórico & até $20 \mathrm{~m} 2 / \mathrm{hab}$ & 20 a $32 \mathrm{~m} 2 / \mathrm{hab}$ & 32 a $50 \mathrm{~m} 2 / \mathrm{hab}$ & $\begin{array}{l}\text { superior a } 50 \\
\mathrm{~m} 2 / \mathrm{hab}\end{array}$ \\
\hline \begin{tabular}{|l} 
Sé \\
Barra Funda \\
Belém \\
Bom Retiro \\
Brás \\
Cambuci \\
Pari \\
República \\
Mooca \\
Santa Ifigênia \\
\end{tabular} & $\begin{array}{l}\text { década } 80 / 90 \\
\text { década } 70 / 80 \\
\text { década } 70 \\
\text { década } 80 \\
\text { década } 70 / 90 \\
\\
\text { década } 70\end{array}$ & $\begin{array}{l}\text { década } 80 \\
\text { década } 70 \\
\text { década } 70 / 80 \\
\text { década } 70 / 80 \\
\text { década } 80\end{array}$ & $\begin{array}{l}\text { década } 70 \\
\text { década } 90 \\
\text { década } 90 \\
\text { década } 90 \\
\text { década } 80 \\
\text { década } 90 \\
\text { década } 90 \\
\text { década } 70 / 80 / 90 \\
\text { década } 90 \\
\text { década } 70 / 80 / 90\end{array}$ & \\
\hline distritos ao redor & & & & \\
\hline $\begin{array}{l}\text { Consolação } \\
\text { Alto de Pinheiros } \\
\text { Lapa } \\
\text { Liberdade } \\
\text { Moema } \\
\text { Bela Vista } \\
\text { Perdizes } \\
\text { Pinheiros } \\
\text { Jardim Paulista } \\
\text { Santa Cecília } \\
\text { Itaim Bibi } \\
\text { Vila Leopoldina } \\
\text { Indianópolis } \\
\text { Aclimação } \\
\text { Jardim América } \\
\text { Cerqueira Cesar } \\
\text { Vila Madalena } \\
\text { Vila Mariana }\end{array}$ & década 70/80 & $\begin{array}{l}\text { década } 70 / 80 \\
\text { década } 80 \\
\text { década } 70 \\
\text { década } 80 \\
\text { década } 70 \\
\\
\text { década } 70 / 80 \\
\text { década } 70 \\
\text { década } 70 / 80\end{array}$ & $\begin{array}{l}\text { década } 70 / 80 \\
\text { década } 70 / 80 \\
\text { década } 90 \\
\text { década } 70 / 90 \\
\text { década } 80 \\
\text { década } 70 / 90 \\
\text { década } 80 \\
\text { década } 70 \\
\text { década } 70 \\
\text { década } 70 / 80 / 90 \\
\text { década } 70 \\
\text { década } 90 \\
\text { década } 70 \\
\text { década } 90 \\
\text { década } 70 \\
\text { década } 70 \\
\text { década } 80\end{array}$ & $\begin{array}{l}\text { década } 90 \\
\text { década } 90 \\
\text { década } 90 \\
\text { década } 90 \\
\text { década } 80 / 90 \\
\text { década } 80 / 90 \\
\text { década } 80 / 90 \\
\text { década } 80 / 90 \\
\text { década } 80 / 90 \\
\text { década } 80 / 90 \\
\text { década } 90 \\
\text { década } 90\end{array}$ \\
\hline
\end{tabular}

2000.

Nota. Informações anteriores à década de 60 não puderam ser agrupadas nos distritos oficiais determinados em 1991.

A evolução ocorrida nessa região, embora tenha contribuído para o processo de evasão da população de menor renda, gerou, ao longo do século XX, a concentração de melhorias em vários aspectos, formando um círculo de investimentos e de constante atração de benfeitorias, e como consequência direta a ocupação da área por grupos de melhor poder aquisitivo, sofisticando os usos e o setor imobiliário, como é resumido no esquema da figura 2: 
Possibilidades de diversos usos do solo

Histórico de investimentos na região central / oeste da cidade

Ocupação pela classe de maior renda

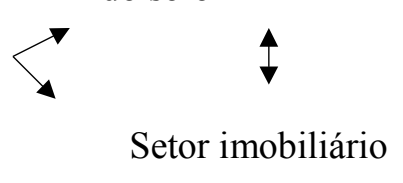

Setor imobiliário

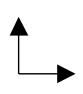

Infra-estrutura

Figura 2. Causas e consequências do desenvolvimento da região. Fonte: Massara, 2002.

\section{Redes de Infraestrutura}

Período 1890-1922

O primeiro relato sobre melhorias na condição das redes data de 1879 , quando do assentamento dos canos para abastecimento de água, ligando o manancial da Cantareira ao reservatório da Consolação (MOTTA, 1911).

Em 1882, foram entregues ao uso público os chafarizes recém construídos do Campo da Luz (avenida Tiradentes), Largo São Bento, Largo do Pelourinho (Sete de Setembro), Largo do Guaianazes (Capão Redondo) e Largo Sete de Abril (Praça da República) que, junto aos antigos, tentavam suprir a cidade, já que não havia verba disponível para o melhor aproveitamento da única fonte - a Cantareira, alguns quilômetros ao Norte...(MORSE, 1970, p.172).

No ano de 1883, a região da Luz é considerada o "primeiro distrito de esgoto". Boa parte das ruas já era servida com redes desde o centro até proximidades da Rua Tenente Pena (próximo a atual Praça Coronel Prestes). A proximidade da Serra da Cantareira propiciava água de boa qualidade. Em 1889, tem início o incremento da canalização domiciliar para a rede de água da região Sé.

Em 1893, todos os chafarizes foram demolidos, como forma de obrigar os usuários a "comprarem" os serviços da concessionária.

Em 1900, a iluminação elétrica é instalada em alguns pontos do centro, chegando a algumas ruas do Bom Retiro e à região de Campos Elíseos, como também em pontos da Consolação em direção à recém inaugurada Avenida Paulista (ELETROPAULO, 1989).

Nesta época, além desse núcleo central de caráter predominantemente comercial, na direção do Brás e Luz, em função da Estrada de Ferro, tinha início a efetiva ocupação da área como bairro operário, além de pequena concentração de comércio, indústrias e armazéns. 
A elite, em busca de terrenos mais altos e na promessa de implantação de infra-estrutura no novo loteamento, vai rumo ao Campos Elíseos, bairro aberto em 1879 e praticamente desocupado até 1890. No período de 20 anos, a área recebeu todos os melhoramentos públicos: iluminação a gás, água, esgoto, arborização e pavimentação das ruas. Em 1910, em pleno funcionamento, com infra-estrutura completa, o bairro está no ápice das considerações sobre qualidade de vida.

Outro empreendimento de grande porte foi a abertura da Avenida Paulista em 1891, um dos únicos empreendimentos que podem mencionar a infra-estrutura como atrativo ao incremento do uso do solo. Foi inaugurada já provida de todos os melhoramentos, enquanto suas transversais e paralelas, funcionando como infra-estrutura de apoio, recebiam tudo que não era "digno" da nobre avenida".

$\mathrm{Na}$ década de 10, o primeiro acontecimento de vulto no desenvolvimento das redes, foi em 1912: a extensão da rede de coleta de esgotos até o Cambuci e Vila Mariana. Foram iniciadas as redes de Perdizes e parte do Ipiranga, finalizadas em 1914. No ano seguinte, Barra Funda e Bom Retiro são servidos e tem início as obras nos bairros da Água Branca, Lapa e Santana (NOVAES, 1927).

Na mesma época (1912), o abastecimento de água também teve boa expansão, embora seja notório que o serviço não conseguia alcançar o ritmo acelerado do crescimento urbano. Bairros como Cambuci, Mooca, Bom Retiro e Barra Funda possuíam a rede, mas com grandes problemas de regularidade. Outras áreas como Vila Mariana, Perdizes, Água Branca e Belenzinho eram totalmente desprovidos. A iluminação alcançava alguns bairros distantes como a Água Branca, Lapa e Ipiranga, mas a preferência para instalação da rede era o centro e as ruas dos melhores bairros.

Simultaneamente, os bairros vão sendo ocupados. A área residencial de elite chega a Higienópolis, as indústrias avançam ao redor da Estrada de ferro, no Pari, Belém, Brás e Mooca: fábricas de bebidas (Antarctica), tecelagens, calçados; e, no sentido oposto na Lapa de Baixo: várias vidrarias, entre elas a Santa Marina. Surge um núcleo comercial expressivo no Brás (entre as Avenidas Bresser e Celso Garcia).

\footnotetext{
${ }^{9}$ Encontramos um relato interessante sobre essa época e a região, descrito por GATTAI (Gattai, Z. Anarquistas Graças a Deus, 1979, p.43): “A Alameda Santos, vizinha pobre da Paulista, herdava tudo aquilo que pudesse comprometer o conforto e status dos habitantes da outra, da vizinha famosa. Os enterros, salvo raras exceções, jamais passavam pela Avenida Paulista. Eram desviados para a Alameda Santos nela desfilavam todos os cortejos fúnebres que se dirigiam ao Cemitério do Araçá, não muito distante dali. Rodas de carroças e patas de burros jamais tocaram no bem cuidado calçamento da Paulista. Tudo pela Alameda Santos Nem as carrocinhas da entrega do pão, nem os burros da entrega do leite, com seus enormes latões pendurados em cangalhas, um de cada lado, passando pela manhã muito cedo, tinham permissão de transitar pela Avenida."
} 


\section{Período 1922-1952}

O ano de 1922 marca a difusão da energia elétrica como fonte para iluminação pública (BRANCO; 1951; ELETROPAULO, 1990).

Aproveitando as facilidades construtivas para expansão das redes, tem início o loteamento da área abaixo da Rua Estados Unidos e delimitada pelas Avenidas Nove de Julho e Brigadeiro Luiz Antonio, como a Avenida Paulista, servido por todos os melhoramentos. As ruas Pamplona e Augusta aparecem como importantes corredores de comércio sofisticado.

Na direção noroeste, a mesma Companhia inicia, em 1920, o loteamento do Alto da Lapa e Bela Aliança na mesma área com padrões inferiores. Surge a Vila Leopoldina que, ao longo desse período, transforma-se em grande área industrial no ramo metalúrgico.

Mesmo sem informações sobre a precisa data de implantação das redes entre 1900 e 1928, fica subentendido que os melhoramentos nos bairros operários foram incrementados na década de 20.

Em 1929, a região de Pinheiros recebe água canalizada. Nos anos seguintes, até 1942, Perdizes, Vila Madalena, Aclimação e Parque da Mooca. A situação da rede de coleta de esgotos alcança esse perímetro somente dez anos mais tarde (1952).

$\mathrm{Na}$ expansão sul da cidade - ínfima nesse período -, a região do Itaim Bibi, loteada em 1920, sem nenhum plano urbanístico ainda em 1951, utilizava poços em áreas mais altas como as Ruas Floriano Peixoto, Pedroso de Albuquerque, Renato Paes de Barros e Clodomiro Amazonas. A água era de boa qualidade e as fossas funcionavam a contento; já nas regiões baixas, para evitar a contaminação, as fossas eram limpas e desinfetadas a cada quinze dias (SABESP, 1936).

Estes dois períodos (1890 -1922; 1922-1952) constituem os anos de maior evolução das redes, embora fique claro que, em apenas três casos, a pré-existência da infra-estrutura estimulou o uso do solo: Avenida Paulista, parte da Vila América ${ }^{10}$ e Alto da Lapa, atraindo o uso residencial de elite.

Em outros casos, mesmo sendo ocupado pela classe de maior renda, a implantação das redes foi consequência da ocupação, como em Higienópolis e Campos Elíseos.

A restrição àinstalação de casas comerciais nos Jardins, limitando as ruas de comércio a Pamplona e Augusta, a instalação de linhas de bonde (1910 - bonde da Rua Augusta e 1924

\footnotetext{
10 Conforme REALE (Reale, E. Brás, Pinheiros e Jardins: três bairros, três mundos. São Paulo, Editora da Universidade de São Paulo, 1982), o perímetro da Vila América corresponde ao atual Jardim Paulista ou a área de Cerqueira César, mais as alamedas paralelas e transversais à Avenida Paulista.
} 
- bonde do Jardim Paulista), somada à reunião de colégios de renome, assim como a instalação de pólos culturais (como o Museu de Arte de São Paulo - 1950) contribuiu para a ocupação residencial de maior poder aquisitivo. Nestas décadas, outros núcleos comerciais são criados: Lapa (região da Rua Guaicucus com Gavião Peixoto e Nossa Senhora da Lapa) e Pinheiros (Rua Pedroso de Morais com Avenida Brig. Faria Lima).

O processo de verticalização da cidade cria uma área residencial mista com comércio ao redor do antigo centro: Pacaembu, Higienópolis, Santa Cecília, Campos Elíseos (já decadente) e Consolação.

O desenvolvimento de funções industriais incentivada pela Estrada de Ferro, e também pela construção das marginais Pinheiros e Tietê, consolidou a Lapa, Barra Funda, Belém, Pari, Brás e Mooca, como bairros tipicamente operários, originando regiões de uso misto (comércio, indústria e residências), principalmente nos últimos três bairros.

\section{Período 1952-1972}

Este período concentra a cobertura de "vazios" em regiões como o Sumaré, em direção a Vila Madalena, pontos dispersos da Barra Funda e pontos da Aclimação até a Vila Mariana. As áreas servidas por abastecimento de água e iluminação pública são aproximadamente coincidentes.

Os mapas de 1958 e 1968 (AZEVEDO, 1958; PMSP-PUB, 1968) mostram pouca evolução em direção ao Itaim Bibi e Planalto Paulista e em parte da Vila Leopoldina e Alto de Pinheiros, de ocupação mais recente. No final desse período, pode-se afirmar que é mínima a deficiência da região no tocante aos dois serviços.

A rede de coleta de esgotos evidencia certa diferença em relação às redes descritas anteriormente. Embora em 1928 houvesse áreas com maior avanço do que a rede de água, somente na década de 60, enfatizou-se a expansão na direção sul (Itaim e Moema). Também a rede de gás demonstrada no mapa de 1958 mantéem-se praticamente a mesma passados dez anos, cobrindo a área central (até a Mooca) e estendendo-se em direção sudoeste até os bairros de Jardins América e Europa e Jardim Paulista. E, como veremos adiante, até a evolução proposta no projeto do final do anos 90, pouca alteração ocorre nesse âmbito nas duas décadas seguintes (COMGÁS, 1997).

Simultanemente, o perfil do uso residencial do solo sofre as transformações oriundas do processo de verticalização iniciado nos anos 60 . 
A inauguração de Shopping Centers, como o Shopping Iguatemi - o primeiro da América Latina - inicia uma nova fase do comércio. Ao mesmo tempo, outros subcentros são criados e inicia-se a popularização do comércio central.

Em 1966, a construção do Ceasa (atual Ceagesp), além de favorecer o abastecimento da cidade, define a região entre as Vilas Leopoldina e Hamburguesa como área de uso misto com concentração de armazéns e residencial modesto, além de indústrias já estabelecidas no período anterior.

Também no início desse período começa a implantação da linha Norte-Sul do Metrô, a qual irá influenciar modificações em boa parte da região em estudo, ressaltando a importância da localização e da acessibilidade como determinantes na escolha de usos e decisão sobre projetos no campo do sistema viário e dos meios de transporte (IBGE, 1970).

\section{Período 1972-1999}

Esse período marca a consolidação das redes de infraestrutura com praticamente toda a área servida por abastecimento de água e iluminação pública. Déficits pontuais são encontrados nas regiões da Barra Funda, Mooca, Lapa de Baixo e Vila Leopoldina. Ainda em 1975, na área central, os problemas com rede de coleta de esgotos estavam localizados em áreas próximas à Marginal do Tietê, em áreas de ocupação desordenada entre a Avenida Rudge e o leito do rio (SABESP, 1976).

A rede de gás, pouco expandida fora do Centro Antigo e Jardins, estende-se à região de Pinheiros ao longo das Avenidas Brigadeiro Luiz Antonio, Nove de Julho, Rebouças e ruas comerciais como a Joaquim Floriano e Pedroso de Moraes. Na Lapa, uma área inexpressiva entre as avenidas Francisco Matarazzo, Sumaré e Pacaembu é beneficiada.

Embora a área seja totalmente servida por iluminação pública, os pontos com pedido de manutenção são inúmeros, conforme informações do Ilume com base no ano de 1997 (2001).

Segundo a SABESP (1999), a região estava 100\% servida por saneamento. Já a rede de gás está em processo de expansão em direção à Lapa e a Santo Amaro.

As mudanças no uso do solo, principalmente quanto ao processo de desindustrialização, transformaram toda a região ao longo da ferrovia em uso misto.

Vários centros comerciais expandiram-se, como o antigo centro estendendo-se até a Avenida Paulista, os centros do Brás, Lapa e da Avenida Brigadeiro Faria Lima.

Com exceção ao Alto da Lapa, parte dos Jardins América e Europa e da região do Itaim Bibi em direção ao Ibirapuera, as áreas eminentemente residenciais de elite cedem 
espaço a regiões com grande concentração de edifícios e comércio (MESQUITA, 1998; NOBRE, 2000).

Como afirma a SEMPLA (2001), com exceção das áreas mais nobres, todas as outras regiões do centro expandido apresentam ocupação mesclada com outros tipos de uso. A predominância de prédios na área abaixo da estrada de ferro ${ }^{11}$ mistura-se a áreas de pequeno comércio, resumindo a ocupação em três grandes grupos: comércio e prestação de serviços; uso residencial, industrial e comercial (uso misto) e residencial e comercial (outro tipo de uso misto).

As figuras 3a, b, c, d, e , f, representam a cobertura das redes no centro expandido.



(a)

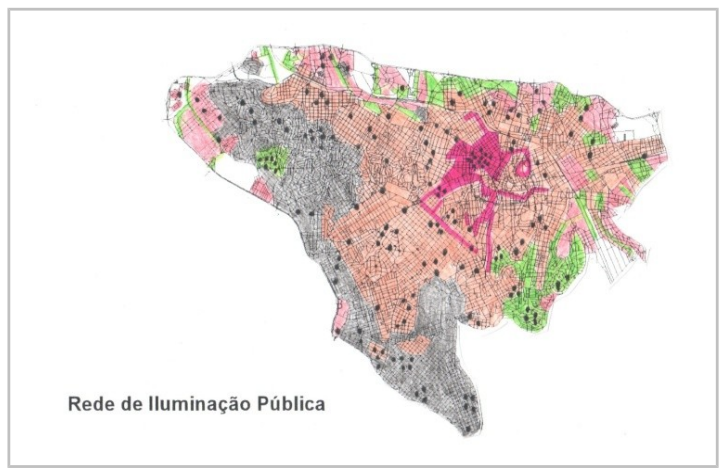

(c)

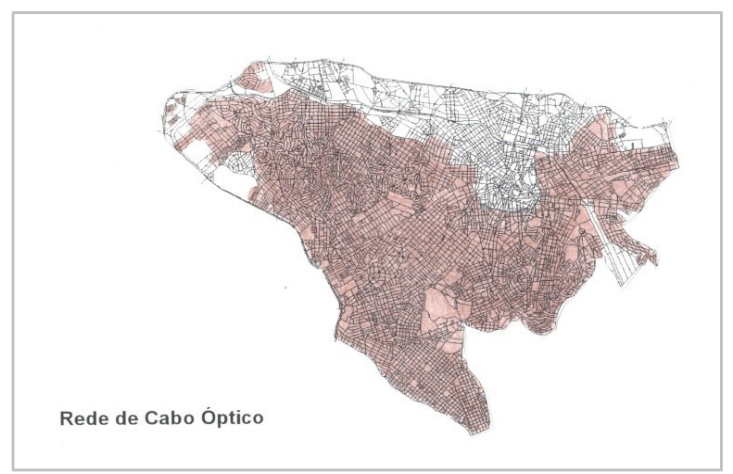

Centrais Telefônicas - 1999/01



(d)




(e)

(f)

Figura 3. Dinâmica da expansão das redes de infraestrutura no centro expandido (cidade de São Paulo). Fonte: Elaboração Massara (2002) a partir de dados: AZEVEDO (1958); COMGÁS (1997); EMPLASA (1977/1998); ILUME (2011); LEÃO, (1941); NET (2001); PMSP (1968;1975; 1986); REVISTA do DAE (1935-1996); SABESP (1999); SEMPLA (1983; 1985); TELEFONICA (2001). Mapa base: Barbosa, 2001.

Nota 1. As legendas não são exatamente iguais para as 4 figuras, visto que as informações para o saneamento básico são mais abrangentes e permitem, assim, um maior detalhamento de sua expansão.

Nota 2. Na figura "rede de iluminaçao pública", os pontos negros significam solicitação de manutenção ao ILUME no ano de 1997. (Com a mesma cor de legenda de 1995 para água e esgoto, e de 1997 para gás canalizado).

Nota 3. A figura "rede de cabo ótico" apresenta apenas uma só data (1999) dada a sua recente implantação datada do final dos anos 90 .

Nota 4. A figura "rede de telefonia" aborda não a cobertura da rede, mas sim o posicionamento das centrais telefônicas de onde partem os ramais de distribuição. Nessa figura, a data é 1999, dada a escassez de informações detalhadas sobre a inserção das centrais nos bairros/distritos nas décadas anteriores.

Nota 5. A rede de energia elétrica é aquela que acompanhou a expansão urbana ( CESP, 1997; ELETROPAULO, 1990) e, por isso, não foi considerada de relevância para mostrar o avanço das redes abordado neste estudo.

Nota 6. Figuras meramente ilustrativas (sem escala). Legendas:

(a), (b), (c) e (d)

$\square \quad 1900$
$\square \quad 1928$
$\square \quad 1942$
$\square \quad 1958$
$\square \quad 1968$
$\square \quad 1975$
$\square \quad 1995$

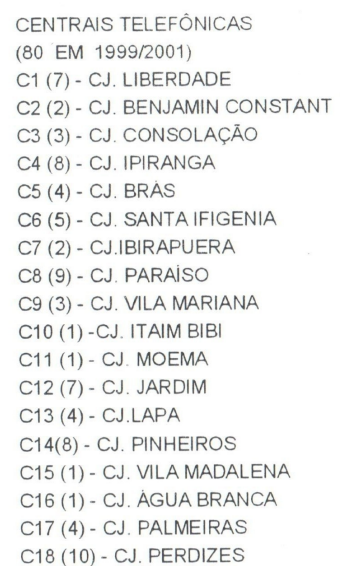

\section{Considerações Finais}

...sendo as áreas centrais as que possuem melhor infraestrutura no município, pode-se concluir que a pressão exercida em seu nome, por investimentos públicos e privados, tende a criar um círculo vicioso de concentração de renda e riqueza no território urbano (SEMPLA, 2001, vol.3 p.42).

Duas observações óbvias podem ser feitas a priori: 
a) A implantação das redes segue uma distribuição concêntrica, partindo do centro antigo. Em geral, áreas comerciais são as primeiras a possuírem todas as redes (provavelmente por este uso se desenvolver a partir do centro);

b) A concentração de renda possibilita usos do solo mais sofisticados e exige a implantação de infraestrutura como cabo óptico e gás canalizado em outras áreas considerada supérflua.

A importância da infraestrutura é difícil de ser mensurada por muitas vezes estar ligada a fatores de caráter subjetivo, como o que cada um entende por qualidade de vida conforme sua realidade. A necessidade do serviço muda conforme o período ou região de estudo. Assim, por exemplo, a importância dada ao saneamento básico no centro histórico data de início do século; já para os distritos ao redor desse primeiro núcleo, concentra-se entre as décadas de 20 e $50^{10}$.

Através desta breve análise, fica explícito que existe uma relação de maior peso envolvendo a implantação das infraestruturas. Essa relação é baseada no conjunto de características da cidade, a começar pela implantação de seu núcleo inicial e consolidação do "centro", culminando com o direcionamento de investimentos visando o setor imobiliário e sua valorização no setor oeste da cidade.

A localização e concentração de renda não são, necessariamente, preponderantes na determinação dos locais que receberão os serviços e na rapidez com os quais serão instalados.

As dificuldades construtivas e a própria expansão rápida e desordenada da cidade impossibilitam o fluxo direto de implantação e criam problemas maiores, como o constante investimento em áreas com déficits e o abandono de outras questões (como a proteção aos mananciais).

Concluímos que o processo de implantação das redes é dependente de diversos fatores que geram um círculo complexo de interesses e real necessidade dos serviços.

\section{Referências}

ANDRADE, Francisco de Paula Dias de. Subsídios para o estudo da influência da legislação na ordenação e na arquitetura das cidades brasileiras. São Paulo, Tese (Livre Docência), Escola Politécnica da Universidade de São Paulo, 1966, pg. 264/272.

AZEVEDO, Aroldo de. (org). A Cidade de São Paulo. São Paulo. Associação dos Geógrafos brasileiros, Companhia Editora Nacional, 1958. Vol II, III, IV. 
BARBOSA, Eunice. Evolução do uso residencial na área central do Município de São Paulo. São Paulo, Dissertação (Mestrado), Escola Politécnica da Universidade de São Paulo, 2001.

BRANCO, Plínio A. O racionamento de energia elétrica. São Paulo, Prefeitura do Município de São Paulo, 1951.

COMPANHIA DE GÁS DE SÃO PAULO - COMGÁS. Gás Natural Mais Energia para São Paulo. São Paulo, (apostila) Comgás, 1997.

COMPANHIA DE SANEAMENTO BÁSICO DO ESTADO DE SÃO PAULO. Revista do DAE. São Paulo, Repartição de Águas e Esgoto de São Paulo - Secretaria de Viação e Obras Públicas. Coleção 1936-1995.

COMPANHIA DE SANEAMENTO BÁSICO DO ESTADO DE SÃO PAULO. Mapa da Rede de Abastecimento de Água, SABESP, 1999.

COMPANHIA DE SANEAMENTO BÁSICO DO ESTADO DE SÃO PAULO. Mapa da Rede de Coleta de Esgotos, SABESP, 1999.

COMPANHIA DE SANEAMENTO BÁSICO DO ESTADO DE SÃO PAULO. Metas para o Abastecimento de Água da Região Metropolitana 1975-78. São Paulo, SABESP, 1976.

COMPANHIA ENERGÉTICA DE SÃO PAULO - CESP. Anuário Estatístico de Energia Elétrica e gás canalizado: consumo por município do Estado de SP. São Paulo, Cesp, 1997.

COTTRELL, William Frederick. Energy and society. Nova Iorque, Mcgraw, 1955.

ELETROPAULO METROPOLITANA ELETRICIDADE E SERVIÇOS. A Cidade da Light 1899-1930. Volumes I e II. São Paulo, Divisão de Preservação do Patrimônio Arquitetônico - Departamento do Patrimônio Histórico, 1990.

ELETROPAULO METROPOLITANA ELETRICIDADE E SERVIÇOS. A Cidade Iluminada: tecnologia e política a serviço da Light no início do século. São Paulo, Divisão de Preservação do Patrimônio Arquitetônico - Departamento do Patrimônio Histórico, 1989.

EMPRESA METROPOLITANA DE ÁGUAS E ENERGIA. Energia Elétrica. São Paulo, EMAE, 2001.

EMPRESA METROPOLITANA DE PLANEJAMENTO - EMPLASA. Sumário de Dados da Grande São Paulo. São Paulo, 1977/1998.

GIOZZA, William F. Fibras ópticas: tecnologia e projeto de sistemas. São Paulo, Makron, 1991.

INSTITUTO BRASILEIRO DE GEOGRAFIA E ESTATÍSTICA - IBGE. Censo Predial. Região Sudeste. São Paulo, IBGE, 1970. 
INSTITUTO BRASILEIRO DE GEOGRAFIA E ESTATÍSTICA - IBGE. Censo 2000. Indicadores socioeconômicos. São Paulo, IBGE, 2000.

LEÃO, Mário Lopes. Revisão das tarifas do serviço Telefonico da Cidade de São Paulo. São Paulo, Revista dos Tribunais, 1941.

MARTINS, Antonio Egídio. São Paulo antigo: 1554 a 1910. São Paulo, Conselho de Cultura, s/d.

MASCARÓ, Juan Luis. Desenho Urbano e custos de urbanização. Brasília, Ministério da Habitação, Urbanismo e Meio Ambiente, 1987.

MASSARA, Vanessa Meloni. O perfil da infra-estrutura no Município de São Paulo e sua relação com as transformações de uso do solo: o centro expandido e a região de São Miguel Paulista. São Paulo, dissertação (mestrado), Engenharia Urbana, Escola Politécnica da Universidade de São Paulo, 2002.

MESQUITA, Lauro. A infra-estrutura completa é o grande patrimônio do centro. Revista Urbs. São Paulo, Associação Viva o Centro, Janeiro, 1998. Pg 36/39.

MORSE, Richard. Formação Histórica de São Paulo. Da comunidade a metrópole. São Paulo, s.ed., 1954.

MOTTA, Arthur. Estudos Preliminares para o reforço do abastecimento d'água na cidade de São Paulo. São Paulo, S.N., 1911.

MUNFORD, Lewis. City in history. Nova Iorque, Horizon, 1961.

MUNFORD, Lewis. The Culture of the cities. Nova Iorque, Harcourt, Brace and company, 1938.

MUSEU DO TELEFONE - COMPANHIA TELEFÔNICA DO ESTADO DE SÃO PAULO. Museu do Telefone. São Paulo, Telesp, 1977.

NET. Cobertura por cabo ótico - Cidade de São Paulo. NET, 1999.

NOBRE, Eduardo Alberto Cuce. Reestruturação Econômica e Território: expansão recente do terciário na Marginal do Rio Pinheiros. São Paulo, Tese (Doutorado), Faculdade de Arquitetura e Urbanismo da Universidade de São Paulo, 2000.

NOVAES, Henrique de. Relatório da Comissão de Obras novas do abastecimento de água da Capital. São Paulo, TYP. Brazil, 1927.

PREFEITURA DO MUNICÍPIO DE SÃO PAULO, PMSP. Plano Urbanístico Básico. Consórcio Asplan, Daily, Montreal, Wilbur Smith, volume.5 - Infra-Estrutura, 1968.

PREFEITURA DO MUNICÍPIO DE SÃO PAULO, PMSP. Administrações Regionais, 16 vol. São Paulo, PMSP, 1975. 
PREFEITURA DO MUNICÍPIO DE SÃO PAULO, PMSP. Planos para cinco regiões administrativas do Município de São Paulo. PMSP, 1986.

SÃO PAULO (CIDADE)- SECRETARIA MUNICIPAL DO PLANEJAMENTO SEMPLA. Atlas Ambiental. Cd-rom. São Paulo, PMSP, 2001.

SÃO PAULO (CIDADE) - SECRETARIA MUNICIPAL DO PLANEJAMENTO SEMPLA. Plano do Município de São Paulo 1985/2000. São Paulo, Prefeitura do Município de São Paulo, SEMPLA. Série Documentos, pg. 126/130, 1985.

SÃO PAULO (CIDADE) - SECRETARIA MUNICIPAL DO PLANEJAMENTO SEMPLA. Diagnóstico regionalizado do município de São Paulo. São Paulo, PMSP, 1983.

TELEFÔNICA. Centrais Telefônicas na cidade de São Paulo no período 1980-1999. São Paulo, 1999.

TELLES, Pedro Carlos da Silva. História da Engenharia no Brasil - século XX. Rio de Janeiro, Clube de Engenharia, vol. 2, 1984.

TOLEDO SILVA, Ricardo. Oferta de infra-estrutura e revitalização do centro: aspectos da gestão e do controle social. São Paulo, São Paulo século XXI, Associação Viva o Centro, 1995. Pg. 19.

ZMITROWICZ, Witold ; ANGELIS NETO, Generoso de. Infra-Estrutura Urbana. São Paulo, Texto Técnico, Escola Politécnica da Universidade de São Paulo, 1997.

ZMITROWICZ, Witold. A estruturação da cidade pelas rotinas urbanas. São Paulo, tese (Livre-Docência), Escola Politécnica da Universidade de São Paulo, 1997. 